\title{
Symptomatic Treatment of Huntington Disease
}

\author{
Octavian R. Adam and Joseph Jankovic \\ Parkinson's Disease Center and Movement Disorders Clinic, Department of Neurology, Baylor College of Medicine, Houston, \\ Texas 77030
}

\begin{abstract}
Summary: Huntington disease (HD) is a progressive heredoneurodegenerative disease manifested by chorea and other hyperkinetic (dystonia, myoclonus, tics) and hypokinetic (parkinsonism) movement disorders. In addition, a variety of psychiatric and behavioral symptoms, along with cognitive decline, contribute significantly to the patient's disability. Because there are no effective neuroprotective therapies that delay the progression of the disease, symptomatic treatment remains the cornerstone of medical management. Several classes of medications have been used to ameliorate the various symptoms of HD, including typical and atypical neuroleptics, dopamine depleters, antidepressants, antiglutamatergic drugs,
\end{abstract}

GABA agonists, antiepileptic medications, acetylcholinesterase inhibitors, and botulinum toxin. Recently, surgical approaches including pallidotomy, deep brain stimulation, and fetal cell transplants have been used for the symptomatic treatment of HD. The selected therapy must be customized to the needs of each patient, minimizing the potential adverse effects. The primary aim of this article is to review the role of the different therapies, both available and investigational, for the treatment of the motor, psychiatric, behavioral, and cognitive symptoms of HD, and to examine their impact on the patient's functionality and quality of life. Key Words: Huntington disease, chorea, treatment, tetrabenazine, review.

\section{INTRODUCTION}

Huntington disease (HD) is a progressive heredoneurodegenerative disease which was described in 1872 by George Huntington. He first observed this autosomal dominant disease on Long Island, New York, in patients from multiple generations, when he made rounds as a boy with his father and then later as a physician himself. Since the discovery of the gene locus near the tip of the short arm of chromosome 4 in 1983 and the cloning of the gene 10 years later, there has been an explosion of knowledge about the genetics of HD, although the exact role of the abnormal gene product huntingtin in neurodegeneration is still not well understood. The mutation responsible for the disease consists of an unstable enlargement of the CAG repeat sequence in the $5^{\prime}$ end of a large gene (210 kb), HTT (alias IT15), which codes for the protein huntingtin. The expanded CAG repeat, located in exon 1, alters huntingtin by elongating its polyglutamine segment near the $\mathrm{NH}_{2}$-terminus. It is beyond the scope of this review to discuss the genetics, pathol-

Address correspondence and reprint requests to: Joseph Jankovic, MD, Professor of Neurology, Director of Parkinson's Disease Center and Movement Disorders Clinic, Department of Neurology, Baylor College of Medicine, 6550 Fannin, Suite 1801, Houston, TX 77030. E-mail: josephj@bcm.tmc.edu. ogy, imaging, and other aspects of the disease, for which the reader is referred to recent reviews. ${ }^{1-3}$

Despite the extraordinary growth of our knowledge about the cellular mechanisms involved in HD-related neurodegeneration, no effective neuroprotective or disease-modifying therapy has emerged. This review therefore focuses primarily on symptomatic therapy. The selection of the most appropriate symptomatic treatment depends on the most dominant or troublesome symptom ${ }^{4}$ (FIG. 1). Patients with HD may exhibit a variety of movement disorders, with the most common being chorea, but also parkinsonism (characteristic of juvenile HD), ataxia, dystonia, bruxism, myoclonus, tics, and tourettism. The psychiatric, behavioral, and cognitive manifestations of the disease are also very debilitating, rendering the patient dependent on others. These include irritability, depression, lack of motivation, paranoia, hallucinations, and cognitive and intellectual decline. Other contributing symptoms to the overall disability are dysphagia, weight loss, dysarthria, and sleep disturbance. ${ }^{1}$

Several clinical rating scales have been developed and validated, and have been used extensively in clinical trials to ensure a uniform assessment of outcomes. The Unified Huntington's Disease Rating Scale (UHDRS), developed by the Huntington Study Group (HSG), comprises several subscales that assess motor function, $\operatorname{cog}$ - 


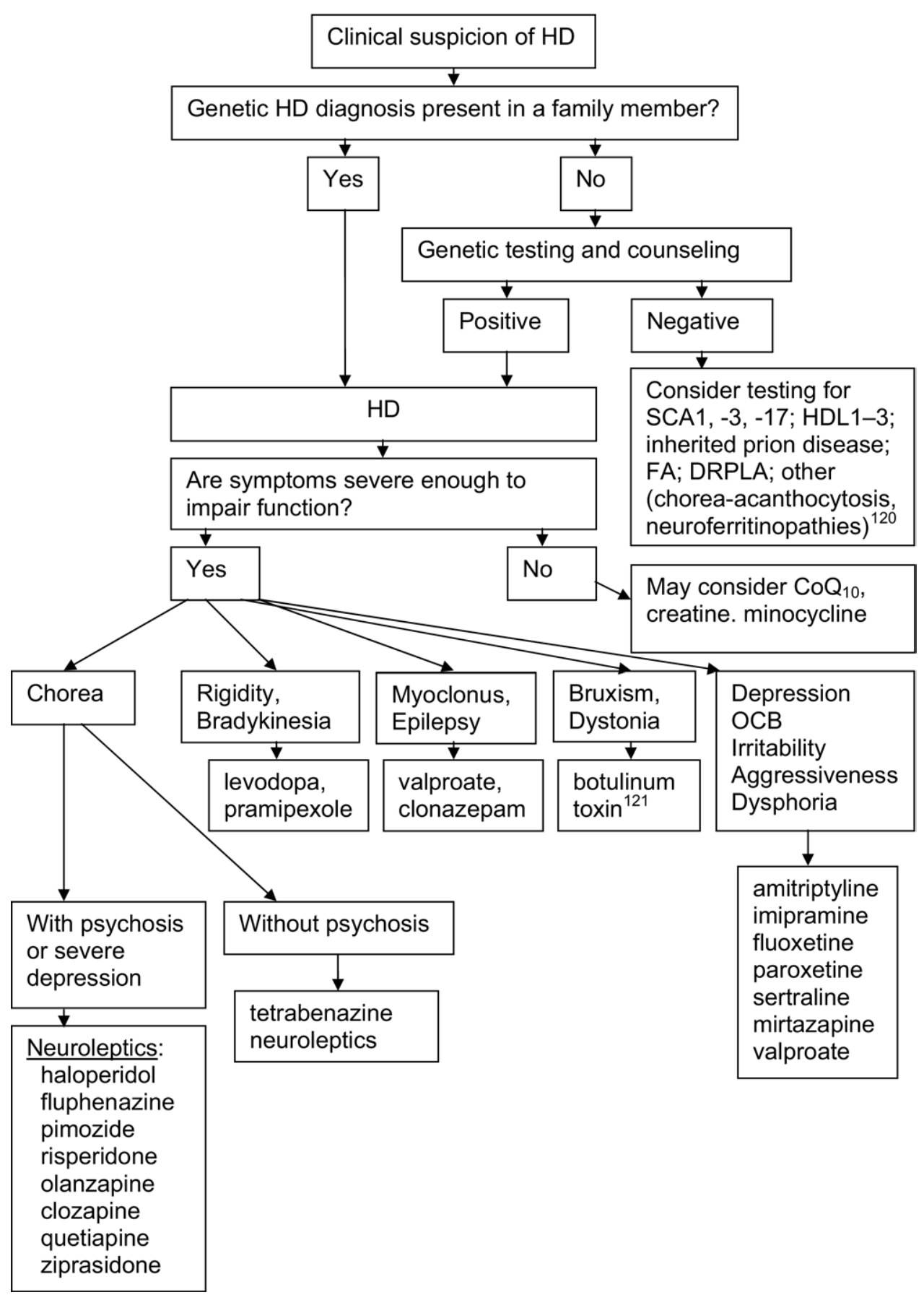

FIG 1. Algorithm for the symptomatic treatment of Huntington's disease. $C_{0} Q_{10}=$ coenzyme $Q_{10}$; DRPLA = dentatorubropallidoluysian atrophy; $\mathrm{FA}=$ Friedreich's ataxia; $\mathrm{HDL}=$ Huntington disease-like syndrome types 1, 2, and 3; OCB = obsessive-compulsive behavior; $\mathrm{SCA}=$ spinal cerebellar ataxia types $1,3,17 .^{120,121}$

nition, behavior, functional status, and independence. ${ }^{5}$ The Abnormal Involuntary Movement Scale (AIMS) uses a rating of 0 (no movement) to 4 (severe) to quantify abnormal movements. ${ }^{6}$ Scores are attributed separately for abnormal movements affecting the muscles of facial expression, lips and perioral area, jaw, tongue, upper extremities, lower extremities, and trunk. The scale also incorporates other items, related to the patient's aware- ness of and disability caused by the abnormal movements, and the presence of dentures or edentia. The functional status of HD patients is commonly assessed using the Total Functional Capacity Scale (TFC) and the Independence Scale (IS), both of which are incorporated into the UHDRS (reproduced in the Appendix).

Because neuroprotective treatments remain elusive, improving the quality of life of HD patients is a priori- 
ty. ${ }^{4,7}$ Intuitively, one might expect that improving motor function would result in an amelioration of functional status in these patients. Such correlation, however, has been difficult to demonstrate. In one study, disease duration, neuropsychological performance (cognitive status), and severity of depression were the factors that correlated best with the rate of decline, ${ }^{8}$ whereas improvement in chorea did not. ${ }^{9}$ Potential explanations include the lack of sensitivity of the existing scales to accurately capture and assess the functional status of HD patients, the occurrence of medication side effects, and the progressive nature of the disease.

Clinical trials involving HD patients often present unique challenges. Enrollment may be difficult, because the disease is relatively rare, and compliance with the protocol has to be carefully monitored to prevent a high drop-out rate. Not surprisingly, only a limited number of randomized clinical trials have been conducted in HD (Table 1). The small sample size (the majority of the studies involved fewer than 30 patients) and the use of different clinical scales (nonvalidated, especially in the older trials, those before 1990) often led to contradictory results, such as in the case of amantadine and its effect on chorea.

The following sections address the shortcomings and strengths of these trials, as well as the existing evidence provided by less rigorously conducted studies and case reports in HD.

Traditionally, neuroleptics and dopamine depleters have been the cornerstone of symptomatic therapy in HD. ${ }^{4,7}$ The atypical neuroleptics tend to be used more frequently in the treatment of HD. Their advantage over the typical neuroleptics is a diminished incidence of the adverse effects familiar in movement disorders (acute dystonia, akathisia, parkinsonism, tardive dyskinesia). The atypical neuroleptics are not necessarily more effective, however, and they may cause more weight gain and other metabolic side effects (e.g., dyslipidemia, increased insulin resistance), resulting in a similar treatment discontinuation rate ${ }^{10}$ as with typical neuroleptics.

\section{DOPAMINE DEPLETERS}

The treatment of hyperkinetic movement disorders, including HD chorea, with dopamine depleters started with reserpine in the 1950s. This drug is not very effective, however, and is poorly tolerated, causing orthostatic hypotension, depression and other adverse effects. Another dopamine depleter, tetrabenazine (TBZ), has largely replaced reserpine. ${ }^{11}$ The first case reports of HD patients improving after treatment with TBZ date to the 1960 s. $^{12,13}$ Since then, numerous case reports and clinical trials, most of them open-label, retrospective or using a small number of subjects, have provided evidence for the benefits of TBZ in the treatment of chorea associated with HD or other causes. ${ }^{14-18}$

Tetrabenazine causes depletion of brain dopamine, norepinephrine, and serotonin by binding to the central, presynaptic, intravesicular portion of the vesicular monoamine transporter VMAT2. Striatal dopamine is the most sensitive to the effects of TBZ. ${ }^{19}$ TBZ inhibits VMAT2 reversibly, accounting for its short duration of action, as opposed to reserpine, which inhibits irreversibly not only the central VMAT2, but also the peripheral VMAT1 (the latter being responsible for some of the peripheral side effects, including orthostatic hypotension and diarrhea). ${ }^{11,20}$

The most compelling evidence for the efficacy of TBZ in HD comes from a multicenter, randomized, doubleblind, placebo-controlled study of $84 \mathrm{HD}$ patients (TETRA-HD), conducted by the HSG. ${ }^{21}$ The patients were randomized 2:1 to receive TBZ or placebo for 12 weeks. The drug was titrated up to the desired antichoreic effect or to the occurrence of side effects. The patients were assessed at 1, 3, 5, 7, 9, 12, and 13 weeks, using the UHDRS chorea score, the Clinical Global Impression Scale, and a newly developed Functional Impact Scale, which assesses bathing, dressing, feeding, toileting and social isolation. The occurrence of parkinsonism was assessed with the Unified Parkinson's Disease Rating Scale (UPDRS); other adverse effects were assessed by other scales, including the Barnes Akathisia Scale, Hamilton Depression Scale, Epworth Sleepiness Scale.

There was a mean $23.5 \%$ reduction in chorea severity from baseline to final evaluation, compared with placebo (placebo corrected, $p<0.0001$ ), the primary outcome of the study. Furthermore, although 2 subjects receiving placebo $(6.9 \%)$ had more than minimal global improvement, 23 TBZ participants $(45.1 \%)$ were more than minimally improved $(p=0.0004)$, which correlated with the improvement in chorea $(p<0.0001)$. There was no significant impact of TBZ on gait or parkinsonism UHDRS scores, nor on the Functional Impact Scale score. Subjects in the TBZ group reported more sleepiness on the Epworth Sleepiness Scale, but no significant change was recorded in the Barnes Akathisia Scale, UHDRS Behavioral Assessment, or UPDRS swallowing and speech items. Chorea worsened at the end of the 1-week washout period (week 13), and there was no difference between the placebo and the TBZ groups, compared with the baseline.

Compliance with the protocol was remarkably high: $93 \%$ of patients completed the study. Reasons for discontinuation of TBZ were suicide (one case; likely situational rather than directly related to TBZ), intracerebral hemorrhage (after a fall), restlessness resulting in hospitalization, breast cancer (the breast lump, present before enrollment, and concealed from the study investigators, was diagnosed as breast cancer during the study), and 
TABLE 1. Randomized Clinical Trials in Huntington's Disease

\begin{tabular}{|c|c|c|c|c|c|c|c|c|}
\hline Study & Medication & Control Agent & Study Design & $N^{*}$ & Effect & $\begin{array}{l}\text { Length of } \\
\text { Study }\end{array}$ & Dose & Assessment Tools \\
\hline $\begin{array}{l}\text { Quinn and Marsden } \\
\text { (1984) }\end{array}$ & sulpiride & placebo & cross-over & 11 & poor & $4 \mathrm{wk}$ & 1200 mg/day & CSS \\
\hline Deroover et al. ${ }^{32}$ (1984) & tiapride & placebo & cross-over & 23 & positive & $3 \mathrm{wk}$ & 3 g/day & subjective \\
\hline Roos et al. $^{33}$ (1982) & tiapride & placebo & cross-over & 22 & none & $2 \mathrm{wk}$ & $300 \mathrm{mg} /$ day & subjective + video \\
\hline McLellan et al. ${ }^{122}$ (1974) & thiopropazate & $\begin{array}{l}\text { placebo, } \\
\text { tetrabenazine }\end{array}$ & cross-over & 9 & positive & $2 \mathrm{wk}$ & $30 \mathrm{mg} /$ day & subjective + video \\
\hline Leonard et al. ${ }^{29}$ (1975) & haloperidol & placebo, lithium & cross-over & 6 & none & $3 \mathrm{wk}$ & $5 \mathrm{mg} /$ day & subjective \\
\hline Caine et al. ${ }^{37}$ (1979) & clozapine & placebo & cross-over & 3 & poor & $4 \mathrm{wk}$ & $\begin{array}{l}\text { Variable } \\
\quad(\max 500 \mathrm{mg} / \text { day })\end{array}$ & subjective \\
\hline Van Vugt et al. ${ }^{36}$ (1997) & clozapine & placebo & cross-over & 26 & poor & $31 \mathrm{~d}$ & $\begin{array}{l}\text { Variable } \\
\quad(\max 150 \mathrm{mg} / \text { day })\end{array}$ & AIMS, UHDRS \\
\hline TETRA-HD; HSG ${ }^{21}$ (2006) & tetrabenazine & placebo & cross-over & 49 & positive & $7 \mathrm{wk}$ & $\begin{array}{l}\text { Variable } \\
\quad(\max 100 \mathrm{mg} / \text { day })\end{array}$ & UHDRS \\
\hline McLellan et al. ${ }^{122}$ (1974) & tetrabenazine & $\begin{array}{l}\text { placebo, } \\
\text { thiopropazate }\end{array}$ & cross-over & 9 & positive & $2 \mathrm{wk}$ & $200 \mathrm{mg} /$ day & subjective + video \\
\hline Jankovic $^{17}$ (1982) & tetrabenazine & placebo & cross-over & 1 & positive & $10 \mathrm{wk}$ & $200 \mathrm{mg} /$ day & subjective + video \\
\hline Lucetti et al. $^{62}$ (2003) & amantadine & placebo & cross-over & 9 & positive & $\begin{array}{l}300 \mathrm{~min} \\
\text { (i.v.) }\end{array}$ & $200 \mathrm{mg}$ i.v./2 h & AIMS, UHDRS \\
\hline Heckmann et al. ${ }^{64}$ (2004) & amantadine & placebo & cross-over & 7 & none & $6 \mathrm{wk}$ & $300 \mathrm{mg} / \mathrm{d}$ & UHDRS \\
\hline $\begin{array}{l}\text { O'Suilleabhain and Dewey } \\
\text { (2003) }\end{array}$ & amantadine & placebo & cross-over & 24 & none & $2 \mathrm{wk}$ & $200 \mathrm{mg} / \mathrm{d}$ & video, chorea scale \\
\hline $\begin{array}{l}\text { Verhagen Metman et al. }{ }^{61} \\
\text { (2002) }\end{array}$ & amantadine & placebo & cross-over & 24 & positive & $2 \mathrm{wk}$ & $400 \mathrm{mg} / \mathrm{d}$ & UHDRS \\
\hline $\begin{array}{l}\text { Landwehrmeyer et al. }{ }^{68} \\
\text { (2007) }\end{array}$ & riluzole & placebo & parallel & 251 & none & 3 years & $100 \mathrm{mg} / \mathrm{d}$ & UHDRS \\
\hline $\mathrm{HSG}^{69}(2003)$ & riluzole & placebo & parallel & 41 & poor & $8 \mathrm{wk}$ & $200 \mathrm{mg} / \mathrm{d}$ & UHDRS \\
\hline $\mathrm{HSG}^{66}(2001)$ & coenzyme $\mathrm{Q}_{10}$ & $\begin{array}{l}\text { placebo, } \\
\text { remacemide }\end{array}$ & parallel & 76 & + trend & $30 \mathrm{mo}$ & $300 \mathrm{mg} / \mathrm{d}$ & UHDRS \\
\hline $\mathrm{HSG}^{66}(2001)$ & remacemide & $\begin{array}{l}\text { placebo, } \\
\text { coenzyme }\end{array}$ & parallel & 66 & + trend & $30 \mathrm{mo}$ & $600 \mathrm{mg} / \mathrm{d}$ & UHDRS \\
\hline Kieburtz et al. ${ }^{65}$ (1996) & remacemide & placebo & parallel & 18 & $\begin{array}{l}+ \text { trend }(200 \\
\text { mg/day) }\end{array}$ & $6 \mathrm{wk}$ & $200 \mathrm{mg} / \mathrm{d}, 600 \mathrm{mg} / \mathrm{d}$ & HDMRS \\
\hline Kremer et al. ${ }^{74}$ (1999) & lamotrigine & placebo & parallel & 28 & none & $30 \mathrm{mo}$ & $400 \mathrm{mg} / \mathrm{d}$ & TFC, QNE \\
\hline Cubo et al. ${ }^{92}(2006)$ & donepezil & placebo & parallel & 12 & none & $12 \mathrm{wk}$ & $10 \mathrm{mg}$ last $6 \mathrm{wk}$ & UHDRS, ADAS \\
\hline Como et al. ${ }^{97}$ (1997) & fluoxetine & placebo & parallel & 12 & none & $4 \mathrm{mo}$ & $20 \mathrm{mg} / \mathrm{d}$ & TFC \\
\hline
\end{tabular}

ADAS = Alzheimer's Disease Assessment Scale; AIMS = Abnormal Involuntary Movement Scale; CSS = Chorea Severity Score; HDMRS = Huntington's Disease Motor Rating Scale; HSG $=$ Huntington Study Group; $\max =$ maximum; i.v. $=$ intravenous; QNE $=$ Quantified Neurological Examination; subjective $=$ nonvalidated subjective chorea scales; TFC $=$ Total Functional Capacity Scale; UHDRS = Unified Huntington's Disease Rating Scale; video = blinded video rating; + trend $=$ trend to positive effect.

*Number of patients in the active arm who completed the study. 
akathisia. Dose-limiting symptoms included sedation (27\%), akathisia (8\%), parkinsonism (4\%), and depression (4\%), which resolved with a decrease in dosage. Subjects receiving less than $50 \mathrm{mg} /$ day of TBZ had a more robust improvement in their chorea than those receiving more than $50 \mathrm{mg} /$ day. Even though the latter group had a statistically significant improvement in chorea, the patients had a slight worsening on the UHDRS Functional checklist and the Functional Impact Scale.

The data regarding the pharmacokinetics of TBZ are sparse. The half-life is relatively short, TBZ being metabolized by first-passage to an active compound, $\beta$-dihydrotetrabenazine (DTBZ), which has a higher bioavailability and longer half-life (10 h, compared with $6 \mathrm{~h}$ for TBZ ${ }^{11}$, but it is not clear if DTBZ is responsible for the central action of TBZ.

The clinical pharmacodynamics of TBZ were studied in an open-label observational study. ${ }^{22}$ Ten patients with HD were assessed with serial motor UHDRS and Beck Depression Inventory at baseline and after their morning dose of TBZ and after at least $12 \mathrm{~h}$ off from their last dose. Chorea was reduced on average by $42.4 \%$, the effect lasting between 3.2 and $8.1 \mathrm{~h}$ (mean $5.4 \pm 1.3 \mathrm{~h}$ ). Therefore, a minimum dosing of 3 times a day may be required to sustain an antichoreic effect without wearing off. The best-tolerated dose of TBZ, necessary to provide adequate control of symptoms, varies greatly between individuals, from as low as $12.5 \mathrm{mg} /$ day to as high as 400 $\mathrm{mg}$ /day. Although no blood levels or other pharmacokinetic data were obtained during this study, the results support previous findings of a short half-life.

The short duration of action of TBZ was also supported by a double-blind study of 30 HD patients, randomly assigned to one of three groups. The first group of 12 patients stopped TBZ (which was replaced with a placebo) on day 1 (withdrawal group), the second group followed the same protocol on day 3 (partial withdrawal), and the third group continued the treatment with TBZ (nonwithdrawal group). ${ }^{23}$ The withdrawal group experienced re-emergent chorea at day 3 , with a difference in the UHDRS change of 5.33 units, compared with 2.94 units in the nonwithdrawal group $(p=0.077)$. The trend toward worsening of chorea after drug withdrawal confirms the efficacy of tetrabenazine.

There is a paucity of data comparing TBZ with the typical neuroleptics in terms of efficacy and safety. In one study of $11 \mathrm{HD}$ patients, TBZ was not superior to haloperidol in improving chorea. ${ }^{24}$ Severe depression occurred in three patients in the TBZ group (one of them committing suicide), and tardive dyskinesia complicated the treatment of three patients in the haloperidol group.

To explore whether TBZ is contraindicated in depression (one of its known adverse effects), a retrospective study examined the effects of TBZ in 518 patients with various hyperkinetic movement disorders, of whom
$52.5 \%$ had a history of depression prior to the treatment. ${ }^{25}$ Of the patients without depression at the time of the treatment initiation, $11.4 \%$ were newly diagnosed with depression, and $18.4 \%$ of the patients with a previous diagnosis of depression at the time when the treatment with TBZ was started had a worsening of their depression. Overall, $15.1 \%$ of patients experienced depression for the first time or had an exacerbation of preexisting depression. Although depression is a known side effect of TBZ and potentially may be exacerbated by TBZ, a diagnosis of pre-existing depression does not constitute an absolute contraindication for initiating treatment if patients are otherwise good candidates, but close monitoring is clearly warranted.

Although dysphagia has been rarely reported as a adverse effect of TBZ, it is often difficult to differentiate this symptom from swallowing problems commonly associated with the underlying disease, as is the case with HD. $^{26}$

Rarely, neuroleptic malignant syndrome has been reported with TBZ, including in HD patients. ${ }^{27,28}$ There are no reports to date of documented tardive dyskinesia induced by TBZ, and this represents a major advantage of this medication over other neuroleptics.

It has been estimated that more than a million people have been treated with TBZ since its introduction in clinical practice more than 50 years ago. Despite a large body of literature documenting the tolerability and safety of this medication, as of 2007 TBZ had not yet been approved by the Food and Drug Administration (FDA) in the United States, although it is available in most European countries, Canada, Mexico and many other countries. Late in 2007, however, an advisory committee of the FDA unanimously recommended TBZ for approval; it is likely that, by the time this article has been published, TBZ will have received FDA approval for the treatment of chorea. This will be the first drug approved specifically for HD.

\section{TYPICAL NEUROLEPTICS}

Typical neuroleptics, including haloperidol, pimozide, fluphenazine, thioridazine, sulpiride, and tiapride, have been used for the treatment of psychotic symptoms as well as chorea in HD. ${ }^{4,7}$ These drugs have a high affinity for D2 dopamine receptors, however, and can potentially induce parkinsonism, akathisia, acute dystonias, and tardive dyskinesia, and so should only be used when absolutely necessary.

There are relatively few well-designed studies assessing the efficacy of the typical neuroleptic drugs in HD, and the outcomes are often contradictory. The earlier studies used nonvalidated rating scales, and the patients enrolled usually did not have a genetically confirmed diagnosis. Also, the majority of these studies had the 
disadvantage of small sample size. Haloperidol was found to have no effect on chorea in a double-blind, randomized, cross-over study of six patients with HD, worsening depression, ${ }^{29}$ but improved chorea was reported in a single-blinded study of $13 \mathrm{HD}$ patients. ${ }^{30}$ Sulpiride improved the movement score, but not the functional status, in a randomized, double-blind crossover trial of 11 patients with HD. ${ }^{31}$ Tiapride was superior to placebo in improving choreic movements and motor skills in a double-blind, placebo-controlled, crossover trial of 29 patients. ${ }^{32}$ The treatment was generally well tolerated, although mild sedation and extrapyramidal signs occurred more frequently in the active treatment group. However, in another 2-week, double-blind, placebo-controlled cross-over study of $22 \mathrm{HD}$ patients, tiapride failed to significantly reduce the involuntary movements. $^{33}$

Higher doses of the typical neuroleptics may not necessarily provide additional benefit in the treatment of chorea, compared with lower doses, but have a potential for a higher incidence of adverse effects, including impairment in the oculomotor, orolingual, motor control, and cognitive functional spheres. ${ }^{34}$

\section{ATYPICAL NEUROLEPTICS}

The atypical antipsychotic drugs have a greater affinity for $5-\mathrm{HT}_{2 \mathrm{~A}}$ serotonin receptors than for D2 dopamine receptors, and so carry a lower risk for extrapyramidal side effects than the typical neuroleptics. ${ }^{35}$ Several atypical antipsychotic drugs have been used in the treatment of chorea and psychiatric symptoms in HD. One of these is clozapine, which has a relatively high affinity for the D4 receptors.

Several studies have assessed the effect of clozapine on chorea in HD. One of the best of these was a doubleblind, randomized trial of $33 \mathrm{HD}$ patients (12 patients were using concomitant neuroleptic medications that were maintained at the same dosage throughout the study). ${ }^{36}$ The patients were administered clozapine (maximum $150 \mathrm{mg} /$ day) or placebo for 31 days, and were evaluated using the AIMS score and the UHDRS-chorea subscore. Only 26 patients ( 8 using concomitant neuroleptic medications) completed the study. Clozapine reduced chorea mildly in the neuroleptic naïve patients only (7.3 reduction on the AIMS, compared with 0 in placebo group), the effect being dose-related. However, voluntary motor performance did not improve and the neuroleptic-naïve patients reported aggravation of functional disability. The occurrence of adverse effects prevented the increase of the clozapine dose to $150 \mathrm{mg} /$ day in most patients, which might have produced a more potent antichoreic effect. All patients claimed to have experienced adverse effects. The most common adverse effects were drowsiness (14 patients), dizziness (6 pa- tients), walking difficulties (6 patients), fatigue (4 patients), hypersalivation (4 patients), increase in liver enzymes (7 patients), and generalized seizure (1 patient).

Another double-blind, placebo-controlled, cross-over study of clozapine involved 12 patients with hyperkinetic movement disorders, 3 of them with HD. Two of the three patients with HD reported improvement in chorea at higher dosages, one at $200 \mathrm{mg} /$ day and one at 500 $\mathrm{mg} / \mathrm{day}$, with rebound of symptoms after discontinuation of the drug. ${ }^{37}$ Both patients, however, experienced significant adverse effects (somnolence, hypotension) that compromised their daily functioning. The third HD patient experienced confusion, disorientation, slurred speech and orthostatic hypotension on $60 \mathrm{mg} /$ day, side effects that subsided upon discontinuation of the drug. Even though this study showed an improvement in chorea on higher doses of clozapine, the very small sample size and the subjective chorea scale used for assessment make these results difficult to generalize.

In another open-label trial, five patients with HD who were administered clozapine $150 \mathrm{mg} /$ day for 3 weeks and were assessed with the AIMS and the Marsden and Quinn chorea scale had mild-moderate improvement of the abnormal movements, in a dose-dependent fashion, and a worsening, back to baseline, once the drug was discontinued at the end of the 3-week study period. ${ }^{38}$ Two case reports document the effectiveness of clozapine in treating psychotic symptoms in HD at doses of $175 \mathrm{mg} /$ day and $200 \mathrm{mg} /$ day, respectively. ${ }^{39,40}$ The role of clozapine in the treatment of HD is questionable, the frequent occurrence of adverse effects preventing the dose escalation for an adequate control of chorea. Also, the mandatory frequent white blood cell count monitoring may prove challenging in HD patients, who are notorious for their poor compliance.

The effect of olanzapine on the motor and psychiatric symptoms of HD was studied in three small, open-label studies. In one study, using between $5 \mathrm{mg}$ and $20 \mathrm{mg}$ per day, nine patients with genetically confirmed HD were evaluated with the UHDRS motor subscale at baseline (after a short, 10- to 18-hour washout in the four patients who had previously been treated with haloperidol) and again at 14 days. ${ }^{41}$ The mean baseline UHDRS score of $54.6 \pm 24.3$ (17-94) decreased after 14 days of treatment to $38.6 \pm 22.7(15-78)(p=0.012)$. The improvement was significant in all items of the motor UHDRS (including chorea), but less for the rigidity, bradykinesia, and dystonia measures. Even though the treatment was well tolerated, the study was short, and follow-up was lost in at least half of the patients at 6 months. Also, the change in the functional UHDRS score was not reported.

The results were replicated in a longer open-label study of 11 patients with HD (8 of them genetically confirmed), treated with a mean of $11.4 \pm 8.5 \mathrm{mg}$ /day of olanzapine. ${ }^{42}$ The motor UHDRS score was reduced 
from $42.4 \pm 14.4$ at baseline to $35.8 \pm 14.1$ at 12 months $(p=0.12)$, this change resulting from substantial improvement in chorea (almost complete, in one patient). Also, the mean behavioral UHDRS score dropped from $31.1 \pm 9.7$ down to $18.1 \pm 9.9$ at 6 and 12 months $(p<$ $0.0001)$. All the patients treated experienced improvement. The treatment was well-tolerated, but 2 of the 11 patients interrupted the treatment due to adverse effects (maculopapular eruption, multiple somatic complaints, and lack of efficacy), and the motor UHDRS score worsened in 3 patients (related to changes in the gait and postural reflex items).

In another open-label, pilot study of 11 patients with genetically confirmed HD and treated with lower doses of olanzapine ( $5 \mathrm{mg} /$ day), there was no significant improvement in chorea, but the behavioral UHDRS score showed a significant improvement, specifically in the depression, anxiety, irritability, and obsession items. ${ }^{43}$

A series of case reports support the positive effect of olanzapine on the motor function and behavioral symptoms in HD patients, with improvement in function (resumption of independence in activities of daily living). ${ }^{44-50}$ These data support the usefulness and tolerability of olanzapine in the treatment of motor and behavioral symptoms of HD, the effect being dose-dependent. Other atypical neuroleptics reported to improve motor and psychiatric symptoms in HD are risperidone,${ }^{51-56}$ quetiapine, ${ }^{57-59}$ and ziprasidone. ${ }^{60}$

\section{ANTIGLUTAMATERGIC DRUGS}

Several antiglutamatergic agents have been tried in HD, but only a few have been subjected to the rigor of controlled design. Amantadine ( $400 \mathrm{mg} / \mathrm{day}$ ) was administered to $24 \mathrm{HD}$ patients (confirmed genetically, or with family history) in a double-blind, placebo-controlled study, with cross-over at 2 weeks. ${ }^{61}$ They were evaluated using the UHDRS, the Mini-Mental State Examination (MMSE), and a cognitive test battery. Blood levels of amantadine were measured $3 \mathrm{~h}$ after the drug intake at 2 and 4 weeks. Appendicular chorea improved most, by $36 \%$ in the 22 patients evaluated, and by $56 \%$ in the 10 patients with the highest plasma levels of amantadine (improvement correlated with the plasma levels). Parkinsonism did not worsen, and there was no effect on cognition. The treatment was well-tolerated, but the occurrence of hallucinations and confusion required a reduction in dosage in some patients.

These positive results were replicated by another randomized, placebo-controlled study of nine patients with genetically confirmed HD who were administered amantadine acutely, as a 2-hour intravenous infusion, in a cross-over fashion. ${ }^{62}$ The patients were evaluated with the AIMS and the UHDRS motor subscale every $15 \mathrm{~min}$ after the infusion, by a blinded rater. There was a sig- nificant drop of approximately $50 \%$ in the AIMS score in the amantadine group, compared with approximately $10 \%$ in the placebo group, at $90 \mathrm{~min}$ after the start of the infusion $(p<0.05)$. The effect was maintained at 300 min. In the open-label, chronic phase of the same study, the patients continued oral amantadine treatment $(300$ $\mathrm{mg}$ /day) for 1 year. There was a moderate improvement in the choreic dyskinesias in all patients. The neuropsychiatric evaluations were not altered by the treatment with amantadine.

Contradictory results were obtained from another randomized, placebo-controlled, double-blind study of 24 genetically confirmed HD patients, treated with amantadine $(300 \mathrm{mg} /$ day $)$ for 2 weeks. ${ }^{63}$ They were evaluated by blinded raters for chorea at rest, using a chorea scale $(0=$ absent, $4=$ marked/prolonged; maximum 24 points). Chorea of the face, neck, trunk, and limbs, analyzed separately, did not improve with amantadine treatment. Adverse effects included insomnia, agitation, anxiety, confusion, diarrhea, sleepiness, and itching. However, the smaller dose $(300 \mathrm{mg} /$ day $)$ used, the slightly different chorea rating scale (face and mouth were not scored separately), and the short patient video recording time $(30 \mathrm{~s}$ at rest and $30 \mathrm{~s}$ while performing mental calculations) may in part explain the differences from the original study (by Verhagen Metman et al. ${ }^{61}$ ).

These negative results were replicated by a smaller, double-blind, placebo-controlled, cross-over study of eight genetically confirmed HD patients. ${ }^{64}$ Treatment with amantadine at $300 \mathrm{mg}$ for 2 weeks did not improve the UHDRS chorea scores between the active group and the placebo group; however, the total UHDRS score improved, secondary to an improvement in the behavior subscores. The results did not reach statistical significance.

The conflicting outcomes of these various studies suggest that amantadine may not be a potent antichorea medication at a dose of less than $400 \mathrm{mg} /$ day.

Remacemide, a nonselective NMDA receptor antagonist, showed a trend toward improvement in chorea at a dose of $200 \mathrm{mg} /$ day, in a double-blind, randomized, placebo-controlled study of 31 patients with HD who were administered remacemide at dosages of $200 \mathrm{mg} /$ day or $600 \mathrm{mg} /$ day. $^{65}$ The HSG conducted a larger doubleblind, randomized, placebo-controlled trial to evaluate the impact of remacemide and coenzyme $\mathrm{Q}_{10}$ on the functional decline of early HD. ${ }^{66}$ In this study, 347 patients with HD were divided into four groups, to receive coenzyme $\mathrm{Q}_{10}(600 \mathrm{mg} /$ day), remacemide (600 mg/day), both, or placebo. All four groups were assessed with the UHDRS at regular intervals during the 30 months of the study. A total of 41 participants withdrew from the study, the most common cause being adverse effects such as psychiatric disturbance, gastrointestinal upset, and dizziness, with remacemide being less well-tolerated than 
coenzyme $\mathrm{Q}_{10}$. The remacemide-treated group had a trend toward reduced chorea, which was noted quite early in the course of treatment and was sustained, but without impact on functional decline.

Memantine, another glutamate receptor antagonist, was studied in a 2-year, multicenter, open-label trial involving 27 patients with HD. ${ }^{67}$ Memantine was titrated up to a dose of $30 \mathrm{mg} /$ day. Compared with baseline, at 24 months the Clinical Global Impression score deteriorated from $3.4 \pm 1.3$ to $4.4 \pm 0.7(p=0.01)$ and HD-ADL score deteriorated from $0.58 \pm 0.45$ to $0.86 \pm 0.59(p=$ $0.04)$. The changes that occurred in ratings on the AIMS, UHDRS, and a video chorea scale $(0=$ slight, $3=$ severe) did not reach statistical significance. The authors postulated a neuroprotective effect of memantine, considering that the major deterioration in the measured parameters (which was overall below the values reported in the literature for untreated HD patients) occurred in the first 12 months, with smaller variations during the second year. It is hard to support such an argument, however, considering that the study was not powered sufficiently for the variables measured and lacked a placebo group. Also, except for the video chorea scale, which was assessed independently by two blinded raters (with inter-rater variation at 1 year, probably due to the short video recording duration, only $30 \mathrm{~s}$ ), all the other assessments were done in a nonblinded fashion by the treating physician.

Another drug in this class, riluzole, an inhibitor of glutamate release, has also been evaluated in patients with HD. In a large, randomized, double-blind placebocontrolled trial, conducted by the European Huntington's Disease Initiative Study Group, 537 genetically confirmed HD patients were randomized 2:1 to receive riluzole $100 \mathrm{mg}$ /day or placebo, for 3 years, and were assessed periodically with the UHDRS. ${ }^{68}$ No concomitant use of other antichoreic medications was allowed; the wash-out period was 1 month. A total of 379 patients completed the study; the main reasons for discontinuation were introduction of additional antichoreic treatment and consent withdrawal. Although well-tolerated, riluzole had no significant effect on chorea, behavioral, cognitive, independence, and functional scores, compared with the placebo group at 3 years or at any other time point during the study.

A higher dose of riluzole (200 $\mathrm{mg} / \mathrm{day})$ was used in an earlier double-blind, multicenter study trial, conducted by the HSG in the United States. ${ }^{69}$ In this trial, 63 patients were randomized to receive riluzole $100 \mathrm{mg} / \mathrm{day}$, $200 \mathrm{mg} /$ day, or placebo for 8 weeks. The main outcome was the change in maximal chorea at 4 and 8 weeks, as measured with the UHDRS. The study was completed by $89 \%$ of subjects. The only serious adverse event was a psychiatric hospitalization of one subject who had received riluzole $200 \mathrm{mg} / \mathrm{day}$.
There was a mild reduction in chorea in the $200 \mathrm{mg} /$ day group, compared with placebo $(-2.2 \pm 3.3$, compared with $+0.7 \pm 3.4)(p=0.01)$, without improvement in functional capacity or the other components of the UHDRS (cognitive, behavioral). The liver enzyme alanine transferase was elevated between 2 and 5 times the upper limit of normal in 7 patients. One patient (receiving $200 \mathrm{mg} /$ day) became symptomatic with abdominal pain and an alanine transferase elevation of more than 5 times the upper limit of normal, which ultimately normalized after the discontinuation of the drug. After adjusting for the concomitant neuroleptic treatments, however, the study failed to demonstrate a significant effect of riluzole $200 \mathrm{mg}$ /day on chorea compared with placebo. The modest benefit of riluzole on HD chorea was thought to be related to an interaction with neuroleptics.

Two other small, open-label studies ${ }^{70,71}$ showed mild improvement in HD chorea using $100 \mathrm{mg} /$ day of riluzole for 6 and 12 weeks, respectively. The positive antichoreic effect was not maintained at 12 months in the second study, but the psychomotor speed and the behavioral dysfunction were reduced. The toxic ingestion of riluzole ( $2.8 \mathrm{~g}$ and $3 \mathrm{~g}$ ) was associated with an amnestic episode in two case reports. ${ }^{72,73}$ This was irreversible in the second case, and the authors speculated that riluzole may have possibly caused permanent hippocampal damage. Thus, overall, these studies failed to show a maintained beneficial effect of riluzole in the treatment of HD.

Another putative glutamate release inhibitor, lamotrigine, was tested in a double-blind, placebo-controlled, randomized study of 64 patients with HD. ${ }^{74}$ The patients were randomized to receive either lamotrigine (400 mg/day) or placebo for 30 months and were assessed with the TFC, the Quantified Neurologic Examination scale, and a battery of cognitive tests. Fifty-five patients completed the study. There was no significant difference in the scores between the active and the placebo groups, although there was a trend toward a decrease in chorea in the lamotrigine group.

Summarizing the evidence provided by studies of glutamate antagonists in HD, none of the agents favorably altered in any meaningful way the symptoms or the function of patients with HD.

\section{GABA AGONISTS}

Pharmacological manipulation of the GABAergic system has generally not been found to be effective in improving chorea or other symptoms of HD. For example, valproic acid was found to be ineffective in treating chorea in HD. ${ }^{75,76}$ Cortical myoclonus, however, a rare but potentially disabling clinical feature of adult HD, was shown in several case reports to improve with valproic 
acid, ${ }^{77}$ clonazepam, ${ }^{78,79}$ or a combination of the two drugs. ${ }^{80}$

In an open-label, pilot study, eight patients with HD, with multifocal myoclonus as a predominant symptom, in addition to chorea and parkinsonian features, were administered valproic acid, and assessed with UHDRS. ${ }^{81}$ In seven patients, the myoclonic hyperkinesia improved in a dose-dependent fashion, with a drop in UHDRS score from an initial 73.1 to $60.2(p=0.042)$. Furthermore, mobility and manual dexterity improved, as assessed by handwriting tests and peg insertion tasks. In three patients, marked reduction in their antidopaminergic medications was possible. In five patients, a moodstabilizing effect of valproic acid could be observed. Therefore, in a subgroup of patients with HD who have myoclonus as a dominant feature, treatment with valproic acid may be warranted, with the potential additional mood stabilizing benefit. It should be noted that this antimyoclonic effect is not specific to HD.

Case reports describing a 39-year-old man and a 52year-old woman with HD, with a disease duration of 8 and 13 years respectively, documented marked improvement in psychotic symptoms on a combination of olanzapine and valproic acid, the patients becoming more cooperative in performing activities of daily living and social activities. ${ }^{48}$ The valproic acid as a mood stabilizer helped reduce the dose of the antipsychotic drug. Baclofen, another anti-GABA agent, was found to be ineffective $(60 \mathrm{mg} /$ day $)$ in the symptomatic control of $\mathrm{HD}$, in a placebo-controlled trial. ${ }^{82}$

Levetiracetam, an antiepileptic agent shown to inhibit neural hypersynchronization, ${ }^{83}$ improved the UHDRS chorea score from $12.6 \pm 3$ at baseline to $6.7 \pm 4.3$ after 48 days of treatment, at a mean dose ( \pm SD) of $2583.3 \pm$ $1020.6 \mathrm{mg} /$ day (maximum $3000 \mathrm{mg} /$ day), in a prospective, open-label study of 12 patients with genetically confirmed HD. ${ }^{84}$ The high drop-out rate (33\%) was due mainly to somnolence. Three patients developed parkinsonism at doses of $500 \mathrm{mg} /$ day and $3000 \mathrm{mg} /$ day, which resolved within 7 days after the drug was discontinued. In another 6-month, open-label study of 15 patients with $\mathrm{HD}$, levetiracetam (2000 $\mathrm{mg} /$ day) added to the therapy with olanzapine showed a trend toward improvement, although it did not reach statistical significance. ${ }^{85}$ Treatment with levetiracetam has the potential of inducing reversible parkinsonism. ${ }^{86,87}$

\section{DOPAMINERGIC TREATMENT}

Bradykinesia and rigidity complicate late stages of $\mathrm{HD}$, and are much more common in the juvenile-onset form (Westphal variant). These symptoms are often masked by the concomitant presence of hyperkinetic movements, such as chorea or dystonia. Parkinsonism is a source of disability in HD, impairing gait, mobility, and balance, as well as dexterity and speed of movement. There are few reports regarding specific treatments for bradykinesia and rigidity. Levodopa,${ }^{88,89}$ pramipexole, ${ }^{90}$ and cabergoline ${ }^{91}$ have been reported to be effective in several case reports, but there are no trials assessing their efficacy in controlling parkinsonism in HD.

\section{ACETYLCHOLINESTERASE INHIBITORS}

Because cognitive decline is part of the natural progression of $\mathrm{HD}$, antidementia drugs such as acetylcholinesterase inhibitors have been examined in this patient population. Donepezil was evaluated in a randomized, double-blind, placebo-controlled study of 30 nondemented patients with HD (genetically confirmed, or with family history). ${ }^{92}$ The patients were administered donepezil at a starting dose of $5 \mathrm{mg}$ /day for 6 weeks and 10 $\mathrm{mg}$ /day for another 6 weeks. In the 24 patients who completed the study, there was no significant improvement in chorea (UHDRS-Motor), cognition (Alzheimer's Disease Assessment Scale), or quality of life (Sickness Impact Profile) in the active group, compared with placebo. Adverse events were almost equally distributed in the two groups, except for the presence of suicidal ideation in the donepezil group (two patients reported suicidal ideation). However, considering that one of the exclusion criteria was the absence of dementia, an improvement in cognition was difficult to appreciate.

In an open-label study, eight patients with genetically confirmed HD and moderate to severe cognitive changes were administered donepezil $5 \mathrm{mg} /$ day for 6 weeks and $10 \mathrm{mg} /$ day for another 6 weeks. ${ }^{93}$ Only half of the patients completed the trial (four had experienced side effects within 4 days after increasing the dosage, including worsening of chorea with increased falls, severe diarrhea, irritability, and anxiety). There was no statistically significant improvement in the subsets of the motor UHDRS, including chorea (two patients developed worsening chorea, which ameliorated upon drug withdrawal). Two patients had slight improvement in memory and concentration on $5 \mathrm{mg} /$ day; however, no statistically significant difference was noted between the neuropsychological tests at baseline and at 6 weeks. Not enough patients were available at 12 weeks to achieve sufficient statistical power to permit any analyses. Only one patient remained on donepezil after the completion of the study.

Rivastigmine was studied in a prospective, open-label, randomized, controlled study of 21 patients with genetically confirmed HD. ${ }^{94}$ They were administered either rivastigmine at a dose of $1.5 \mathrm{mg}$ twice-a-day for the first 2 months and increased to $3 \mathrm{mg}$ twice-a-day for the next 6 months, or no treatment, at a 2:1 ratio. They were assessed at baseline and every 2 months, until the end of the study, using MMSE, the Marsden and Quinn chorea 
scale, the TFC score, and the AIMS. The clinical evaluations were done by blinded raters. Four patients dropped out, one because of adverse effects (nausea and diarrhea), and three were lost to follow up. The MMSE, however, showed a statistically significant improvement in patients randomized to the rivastigmine group, compared with the control group, by approximately 1 point $(p$ $<0.05)$. The difference is only minimally meaningful in clinical practice, however, and does not justify recommending this treatment in patients with HD. The other assessments showed no change.

The same patients were evaluated at 2 years. A trend toward improvement was noted in the treated group as opposed to a trend toward worsening in the nontreated group in the TFC and MMSE scores. The worsening in the AIMS scores in the untreated group was significant, compared with scores in the active group, which showed a significant reduction of the involuntary movements at an earlier assessment at 12 months. The motor UHDRS chorea subscore was significantly improved in the rivastigmine group $(10.72 \pm 3.79$ to $6.63 \pm 3.83, p<$ $0.001)$, whereas it increased in the control group (10.8 \pm 1.16 to $15.33 \pm 1.16, p<0.001)$. However, a potential imbalance in the concurrent neuroleptic regimen between the treated and the control group in respect to the number, type, and dosage of the neuroleptics used, may possibly have contaminated the more favorable motor outcome in the treated group.

Galantamine ( $24 \mathrm{mg} /$ day) was reported to improve both the psychotic symptoms and chorea in a 35-year-old man with genetically diagnosed HD, given as a replacement therapy after a month of treatment with haloperidol decanoate for an acute psychotic episode. ${ }^{95}$ Cognitive function remained unchanged. The treatment was well tolerated.

The treatment of HD with acetylcholinesterase inhibitors did not significantly alter motor symptoms or cognitive decline, and had little impact on daily functioning of the HD patients, and therefore these drugs have no specific indication in the treatment of this disease.

\section{ANTIDEPRESSANTS}

Depression is a frequent psychiatric comorbidity in patients with HD, one that may lead to suicide ideation, and its occurrence correlates with the rate of disease progression. Amitriptyline and imipramine, tricyclic antidepressants previously used in the treatment of depression in HD, are seldom prescribed today. There are a few reports on the effect of the selective serotonin reuptake inhibitors (SSRIs).

Paroxetine was reported to be effective in treating obsessive-compulsive symptoms at a dose of $40 \mathrm{mg} /$ day in a 50-year-old patient with HD. ${ }^{96}$ Fluoxetine was studied in a randomized, double-blind, placebo-controlled trial of 30 nondepressed HD patients (Hamilton Depression Inventory score $<16$ ), at a dose of $20 \mathrm{mg}$ /day, for general efficacy in HD. ${ }^{97}$ At 4 months, seven patients did not finish the trial (one experienced agitation and insomnia, two developed severe depression requiring alternative therapy, and four were lost to follow up). No differences were found between fluoxetine and placebo in terms of TFC, neurological performance, or cognitive ratings. However, the study was limited in terms of duration and sample size, and had insufficient power to detect a statistically significant effect.

There are also several conflicting reports regarding the effects of fluoxetine on chorea. A report of two patients with genetically confirmed HD from the same extended pedigree were administered fluoxetine $20 \mathrm{mg} /$ day for disabling obsessive-compulsive disorder. ${ }^{98}$ Both patients had a sustained improvement in UHDRS chorea score (by 8 and 5 points), with prompt worsening on attempts to discontinue the drug. However, in the case of a 46-year-old man with genetically confirmed HD who was treated with fluoxetine $20 \mathrm{mg}$ daily for new-onset disabling obsessive-compulsive disorder, chorea worsened within several days after initiating the treatment, although his decline was not quantified. ${ }^{99}$ Fluoxetine was effective in treating depression in one patient, given in combination with L-deprenyl. ${ }^{100}$ Sertraline may improve obsessive ideas, dysphoria, ${ }^{101}$ irritability and aggressiveness ${ }^{102}$ in patients with HD, but data are limited to case reports. Mirtazapine and electro-convulsive therapy were also found to be effective in treating symptoms of depression, based on case reports. ${ }^{103,104}$

There is still a paucity of information available regarding treatment of mood and anxiety disorders in HD patients, despite the high prevalence of depression in this population. Although anecdotal evidence supports the use of newer generation antidepressant drugs such as paroxetine, fluoxetine, sertraline, and mirtazapine, rigorous trials are urgently needed to objectively demonstrate their efficacy, considering that suicide remains an important complication of HD.

\section{DEEP BRAIN STIMULATION}

Deep brain stimulation (DBS) of the globus pallidus pars interna (GPi) has been an effective treatment of dyskinesias in Parkinson's disease and dystonia. Bilateral GPi DBS in HD was first used in the treatment of a 43-year-old patient, with genetically confirmed HD, who had rapidly progressive disabling chorea despite medical treatment (TBZ, haloperidol, amantadine) and had no psychiatric symptoms. ${ }^{105}$ Chorea and dystonia improved considerably with low-frequency stimulation $(40 \mathrm{~Hz})$, at an amplitude between 2.5 and $3.5 \mathrm{~V}$. Higher frequency $(130 \mathrm{~Hz})$ stimulation resulted in additional improvement 
in chorea and dystonia, but was associated with worsening of bradykinesia.

Positive results of bilateral GPi DBS were reported in a second HD patient with debilitating choreoathetoid movements, refractory to medical management (TBZ, neuroleptics, minocycline), and without psychiatric comorbidities. ${ }^{106}$ The best clinical effects were obtained with high-frequency stimulation $(180 \mathrm{~Hz})$, at an amplitude of 2.8 V. Stimulation at a lower frequency $(40 \mathrm{~Hz})$ resulted in worsening of the hyperkinetic movements. Body weight, mood, energy, and performance of activities of daily living were also positively affected. The effects were maintained at 1 year, but the patient eventually developed progressive hypokinetic symptoms.

Even though GPi DBS was shown to have a positive short-term effect on the hyperkinetic symptoms in HD, it is difficult to predict the long-term impact of this procedure and to determine the optimal stimulation parameters.

\section{FETAL CELL TRANSPLANTATION}

After the positive experience of human fetal mesencephalic tissue transplants in Parkinson's disease in open-label protocols, several studies assessed the safety and efficacy of striatum fetal cell transplants. Preliminary reports documented a slower rate of decline after fetal cell implantation in HD. ${ }^{107-109}$

In one study, five patients with genetically confirmed $\mathrm{HD}$, with minimal cognitive impairment, underwent unilateral (nondominant hemisphere) fetal cell graft implantation, mostly precommissurally in putamen and caudate. ${ }^{110}$ Postsurgical complications included transient confusion, face and upper limb paresis, and slight postural instability. Postoperative magnetic resonance imaging did not detect any complications. All patients started immunosuppressive treatment with cyclosporine, azathioprine, or prednisolone, but most failed to take their medications regularly and reliably. No specific morbidity was associated with the procedure.

One year after the first procedure the patients were implanted with fetal cells in the dominant side. They were assessed with UHDRS, a motor deficit tool (40 continuous alternative movements of each hand between two targets $30 \mathrm{~cm}$ apart), neuropsychological test battery, psychiatric examinations, and magnetic resonance imaging. Their performance was compared with a cohort of 20 patients with HD who did not undergo fetal cell transplant. ${ }^{111}$

At 1 year after the second surgery, fluorodeoxyglucose positron emission tomography (FDG-PET) showed an increase or stability in metabolism, suggesting metabolically active neural grafts in three of the five patients with transplants, compared with the annual $7 \%$ loss in striatal metabolic activity recorded in the control group. The same three patients maintained several neuropsychological results in the normal range, improved their activities of independent living, had a slower decline rate of the UHDRS (chorea and bradykinesia) scores, compared with the HD control cohort, but lost 1 point on the TFC scale. The other two transplant patients deteriorated at the same rate as the control patients.

The same patients (except for one, who died after 4 years) were followed at 6 years. ${ }^{112}$ Chorea plateaued in two patients and worsened, after an initial 4-year improvement, in another patient. Dystonia steadily worsened. Cognitive performance remained stable on nontimed tests and worsened on the timed ones. The TFC decreased by 1 point at 6 years. FDG-PET revealed increased diffuse brain hypometabolism, with relative preservation of the benefit achieved in the parts of striatum.

In another open-label study, seven patients with genetically confirmed HD and without dementia underwent staged, bilateral, fetal striatal tissue transplantation, mostly in the postcommissural putamen, followed by treatment with cyclosporine for 6 months. ${ }^{113}$ They were evaluated using UHDRS and a battery of neuropsychological tests, and underwent PET scanning. Three patients developed subdural hemorrhage, requiring evacuation. One patient experienced a transitory increase in blood urea nitrogen and creatinine that required a temporary reduction in the cyclosporine dose.

At 12 months, the UHDRS score decreased from 32.9 \pm 6.2 to $29.7 \pm 7.5$. The mean annual rate of motor UHDRS score worsening was $5.7 \pm 5.3$ units per year before transplantation and $1.8 \pm 8.9$ units per year after transplantation $(p=0.31)$. Mean TFC scores were $6.6 \pm$ 1.0 at baseline and $7.0 \pm 2.2$ at 12 months $(p=0.46)$. The mean annual rate of TFC score change was $-1.1 \pm$ 1.7 units per year before transplantation, compared with $+0.25 \pm 1.3$ units per year after transplantation $(p=$ $0.06)$.

One of the seven patients died from cardiovascular disease at 18 months after the transplant. The postmortem autopsy of the caudate-putamen demonstrated surviving transplanted cells, with typical morphology, without evidence of immune rejection, and without any evidence of aggregates of huntingtin. ${ }^{114}$ Similar pathologic findings were reported after the autopsy of the caudate and putamen of two HD patients who died at 74 and 79 months after the fetal tissue transplantation, confirming the survival of the grafts in the human striatum for more than 6 years, without evidence of graft rejection and without accumulation of ubiquitin-staining inclusions. ${ }^{115}$ However, the graft integration in the host striatum was poor, possibly explaining the modest clinical improvement in these patients. There are no autopsy reports available from patients receiving transplanted porcine fetal striatal cell transplants ${ }^{116}$ that would allow 
pathology comparisons between allografts and xenografts.

These initial human clinical study results must interpreted with caution. The studies used small numbers of patients, were unblinded, and lacked controls, and therefore were prone to placebo effects and biases. It is premature to set any clinical guidelines regarding the utility of fetal graft transplant in HD, and larger, blinded studies are needed, with longer follow-ups. The procedure seems safe, although risks exist, and these initial results are modest but promising - although much can be learned from the Parkinson's disease experience with doubleblind sham surgeries. The poor compliance of HD patients with the immunotherapy in one of the studies, ${ }^{111}$ and the lack of pathological evidence of graft rejection by the host tissue on autopsy, make the utility of immunosuppressive therapy debatable.

\section{SUMMARY}

In conclusion, HD is a progressive heredodegenerative disease, with considerable disability caused by the multiplicity of hyperkinetic and hypokinetic move- ment disorders, behavioral and psychiatric symptoms, and cognitive decline, all of which compromise the patient's functional status and lead to dependence on others. The care of an HD patient requires a multidisciplinary approach, although the immediate family usually carries the brunt of the burden. Neuroprotective therapies in HD are still elusive, and to date there are no drugs to developed to slow down or to prevent the progression of the disease. ${ }^{4,7}$ Recent studies suggest that abnormal $\mathrm{Ca}^{2+}$ signaling may be directly linked with the degeneration of medium spiny neurons in the caudate nucleus in HD; therefore, calcium channel blockers could have a therapeutic potential for treatment of HD. ${ }^{117,118}$

Gene therapies or the use of viral vectors to deliver genes for trophic factors such as brain-derived neurotrophic factor, ciliary neurotrophic factor, neurotrophin, or neurturin are now considered to be positioned for clinical trials. ${ }^{119}$ In using symptomatic therapies, it is important to customize the therapy and tailor it to the needs of each patient, and to closely monitor for emergence of adverse effects.

APPENDIX. UHDRS: Unified Huntington Disease Rating Scale. Reprinted with permission of Wiley-Liss, Inc., a subsidiary of John Wiley \& Sons, Inc.

\begin{tabular}{ll}
\hline \multicolumn{1}{c}{ Name: } & \multicolumn{1}{c}{ Site \#: } \\
\hline I. MOTOR ASSESSMENT $(0-4)$ & \\
1. OCULAR PURSUIT & a. Horizontal \\
2. SACCADE INITIATION & b. Vertical \\
a. Horizontal & b. Vertical \\
3. SACCADE VELOCITY & a. Horizontal \\
4. DYSARTHRIA & b. Vertical \\
5. TONGUE PROTRUSION & \\
6. FINGER TAPS & a. Right \\
7. PRONATE/SUPINATE-HANDS & b. Left \\
8. LURIA & a. Right \\
9. RIGIDITY-ARMS & b. Left \\
10. BRADYKINESIA-BODY & \\
11. MAXIMAL DYSTONIA & a. Right \\
& b. Left \\
& a. Trunk \\
12. MAXIMAL CHOREA & b. RUE \\
& c. LUE \\
& d. RLE \\
& e. LLE \\
a. Face \\
13. GAIT & b. BOL \\
& c. Trunk \\
d. RUE
\end{tabular}


Appendix (Continued). UHDRS: Unified Huntington Disease Rating Scale. Reprinted with permission of Wiley-Liss, Inc., a subsidiary of John Wiley \& Sons, Inc.

\begin{tabular}{ccccc}
\hline Name: & Site \#: & Date & Date \\
\hline
\end{tabular}

14. TANDEM WALKING

15. RETROPULSION PULL TEST

16. WEIGHT $(\mathrm{kg})$

17. DIAGNOSIS CONFIDENCE LEVEL

18. Motor Examiner

II. COGNITIVE ASSESSMENT

19. VERBAL FLUENCY TEST

20. SYMBOL DIGIT MODALITIES TEST

21. Stroop Color Naming

22. Stroop Word Reading

23. Stroop Interference

24. Cognitive Examiner

III. BEHAVIORAL ASSESSMENT $(0-4)$

25. DEPRESSED MOOD

26. LOW SELF-ESTEEM/GUILT Frequency

27. ANXIETY

28. SUICIDAL THOUGHTS

29. DISRUPTIVE OR AGGRESSIVE BEHAVIOR

30. IRRITABLE BEHAVIOR

31. PERSEVERATIVE/OBSESSIONAL THINKING

32. COMPULSIVE BEHAVIOR

33. DELUSIONS

34. HALLUCINATIONS

\section{APATHY}

36. Does the examiner believe the subject is confused?

37. Does the examiner believe the subject is demented?

38. Does the examiner believe the subject is depressed?

39. Does the subject require pharmacotherapy for depression?

40. Does the subject require pharmacotherapy for irritability?

41. Was the Behavioral Assessment information obtained from: $(1=$ Subject only, $2=$ Subject and family/companion)

42. Behavioral Examiner

IV. FUNCTIONAL ASSESSMENT $(1=$ Yes, $2=\mathrm{No}$ )

43. Could subject engage in gainful employment in his/her accustomed work?

44. Could subject engage in any kind of gainful employment?

45. Could subject engage in any kind of volunteer or non gainful work?

(raw score)

(raw score)

(number correct)

(number correct)

(number correct)
a. Frequency
b. Severity
a. Frequency
b. Severity
a. Frequency
b. Severity
a. Frequency
b. Severity
a. Frequency
b. Severity
a. Frequency
b. Severity
a. Frequency
b. Severity
a. Frequency
b. Severity
a. Frequency
b. Severity
a. Frequency
b. Severity
a. Frequency
b. Severity
(1=Yes, $2=\mathrm{No}$ )
$(1=$ Yes, $2=$ No $)$
$(1=$ Yes, $2=$ No $)$
$(1=$ Yes, $2=$ No $)$
$(1=$ Yes, $2=$ No $)$ 
Appendix (Continued). UHDRS: Unified Huntington Disease Rating Scale. Reprinted with permission of Wiley-Liss, Inc., a subsidiary of John Wiley \& Sons, Inc.

\begin{tabular}{ccccc}
\hline Name: & Site \#: & Date & Date \\
\hline
\end{tabular}

46. Could subject manage his/her finances (monthly) without any help?

47. Could subject shop for groceries without help?

48. Could subject handle money as a purchaser in a simple cash (store) transaction?

49. Could subject supervise children without help?

50. Could subject operate an automobile safely and independently?

51. Could subject do his/her own housework without help?

52. Could subject do his/her own laundry (wash/dry) without help?

53. Could subject prepare his/her own meals without help?

54. Could subject use the telephone without help?

55. Could subject take his/her own medications without help?

56. Could subject feed himself/herself without help?

57. Could subject dress himself/herself without help?

58. Could subject bathe himself/herself without help?

59. Could subject use public transportation to get places without help?

60. Could subject walk to places in his/her neighborhood without help?

61. Could subject walk without falling?

62. Could subject walk without help?

63. Could subject comb hair without help?

64. Could subject transfer between chairs without help?

65. Could subject get in and out of bed without help?

66. Could subject use toilet/commode without help?

67. Could subject's care still be provided at home?

68. Was the Functional Assessment information obtained from: (1=Subject only, $2=$ Subject and family/companion)

V. INDEPENDENCE SCALE (see Key A)

69. Please indicate the most accurate current level of subject's independence

VI. FUNCTIONAL CAPACITY
70. OCCUPATION
71. FINANCES
72. DOMESTIC CHORES
73. ADL
74. CARE LEVEL
$(0-3)$
$(0-3)$
$(0-2)$
$(0-3)$
$(0-2)$

75. Was the Functional Capacity information obtained from: $(1=$ Subject only, $2=$ Subject and family/companion)

76. Functional Examiner

(Appendix continues) 
Appendix (Continued). UHDRS: Unified Huntington Disease Rating Scale. Reprinted with permission of Wiley-Liss, Inc., a subsidiary of John Wiley \& Sons, Inc.

\begin{tabular}{|c|c|c|c|c|}
\hline Name: & Site \#: & Date & Date & Date \\
\hline \multicolumn{5}{|l|}{ VII. CLINICAL SUMMARY } \\
\hline 77. What was the purpose of this visit? & (see Key B) & & & \\
\hline $\begin{array}{l}\text { 78. Since your last assessment of the } \\
\text { subject,in your opinion, has the subject: }\end{array}$ & (see Key C) & & & \\
\hline $\begin{array}{l}\text { 79. Since your last assessment does the } \\
\text { subject feel: }\end{array}$ & (see Key C) & & & \\
\hline $\begin{array}{l}\text { 80. Based on the entire UHDRS do you } \\
\text { believe with a confidence level } \\
>=99 \% \text { that this subject has manifest } \\
\text { HD? }(1=\text { Yes, } 2=\text { No })\end{array}$ & & & & \\
\hline \multicolumn{5}{|l|}{ 81. Comments } \\
\hline \multicolumn{5}{|l|}{ 82. Examiner } \\
\hline VIII. CLINICAL DISPOSITION & $(1=$ Yes, $2=$ No $)$ & & & \\
\hline \multicolumn{5}{|l|}{$\begin{array}{l}\text { 83. a. Since the last visit, has the subject } \\
\text { been permanently institutionalized? }\end{array}$} \\
\hline \multicolumn{5}{|l|}{ b. If the subject was institutionalized will } \\
\hline $\begin{array}{l}\text { the subject continue to be assessed for } \\
\text { this database? }\end{array}$ & & & & \\
\hline
\end{tabular}

\section{REFERENCES}

1. Fahn S, Jankovic J. Huntington disease. In: Principles and practice of movement Disorders. Philadelphia: Churchill Livingstone/ Elsevier, 2007:369-392.

2. Kenney C, Powell S, Jankovic J. Autopsy-proven Huntington's disease with 29 trinucleotide repeats. Mov Disord 2007;22:127130.

3. Walker FO. Huntington's disease. Lancet 2007;369:218-228.

4. Jankovic J. Huntington's disease. In: Noseworthy JH, editor-inchief. Neurological therapeutics: principles and practice. 2 nd ed. London: Informa Healthcare, 2006:2869-2881.

5. Huntington Study Group. Unified Huntington's Disease Rating Scale: reliability and consistency. Mov Disord 1996;11:136-142.

6. Guy W. Abnormal involuntary movement scale. EDCEU Assessment Manual for Psychopharmacology. Washington, DC: U.S. Dept. of Health, Education and Welfare, 1976:534-537.

7. Bonelli RM, Hofmann P. A systematic review of the treatment studies in Huntington's disease since 1990. Expert Opin Pharmacother 2007;8:141-153.

8. Marder K, Zhao H, Myers RH, et al.; Huntington Study Group. Rate of functional decline in Huntington's disease [Erratum in: Neurology 2000;54:1712]. Neurology 2000;54:452-458.

9. Feigin A, Kieburtz K, Bordwell K, et al. Functional decline in Huntington's disease. Mov Disord 1995;10:211-214.

10. Lieberman JA, Stroup TS, McEvoy JP, et al.; Clinical Antipsychotic Trials of Intervention Effectiveness (CATIE) Investigators. Effectiveness of antipsychotic drugs in patients with chronic schizophrenia. N Engl J Med 2005;353:1209-1223.

11. Kenney C, Jankovic J. Tetrabenazine in the treatment of hyperkinetic movement disorders. Expert Rev Neurother 2006;6:7-17.

12. Møller-Christensen B, Videbech T. Treatment of Huntington's chorea with tetrabenazine (Nitoman) [In Danish]. Ugeskr Laeger 1963;125:207-209.

13. Dalby MA. Effect of tetrabenazine on extrapyramidal movement disorders. Br Med J 1969;2:422-423.

14. Paleacu D, Giladi N, Moore O, Stern A, Honigman S, Badarny S. Tetrabenazine treatment in movement disorders. Clin Neuropharmacol 2004;27:230-233.

15. Ondo W, Tintner R, Thomas M, Jankovic J. Tetrabenazine treatment for Huntington's disease-associated chorea. Clin Neuropharmacol 2002;25:300-302.

16. Jankovic J, Orman J. Tetrabenazine therapy of dystonia, chorea, tics and other dyskinesias. Neurology 1988;38:391-394.

17. Jankovic J. Treatment of hyperkinetic movement disorders with tetrabenazine: a double-blind cross-over study. Ann Neurol 1982;11:41-47.

18. Asher SW, Aminoff MJ. Tetrabenazine and movement disorders. Neurology 1981;31:1051-1054.

19. Pettibone DJ, Totaro JA, Pflueger AB. Tetrabenazine-induced depletion of brain monoamines: characterization and interaction with selected antidepressants. Eur J Pharmacol 1984;102:425430 .

20. Tomlinson DR. The mode of action of tetrabenazine on peripheral noradrenergic nerves. Br J Pharmacol 1977;61:339-344.

21. Huntington Study Group. Tetrabenazine as antichorea therapy in Huntington disease: a randomized controlled trial. Neurology 2006;66:366-372.

22. Kenney C, Hunter C, Davidson A, Jankovic J. Short-term effects of tetrabenazine on chorea associated with Huntington's disease. Mov Disord 2007;22:10-13.

23. Frank S, Ondo W, Fahn S, et al. A study of chorea after tetrabenazine withdrawal in patients with Huntington's disease. Clin Neuropharmacol 2008 (in press).

24. Giménez-Roldán S, Mateo D. Huntington disease: tetrabenazine compared to haloperidol in the reduction of involuntary movements [In Spanish]. Neurologia 1989;4:282-287.

25. Kenney C, Hunter C, Mejia N, Jankovic J. Is history of depression a contraindication to treatment with tetrabenazine? Clin Neuropharmacol 2006;29:259-264.

26. Snaith RP, Warren HD. Treatment of Huntington's chorea with tetrabenazine. Lancet 1974;1(7854):413-414.

27. Mateo D, Muñoz-Blanco JL, Giménez-Roldán S. Neuroleptic malignant syndrome related to tetrabenazine introduction and haloperidol discontinuation in Huntington disease. Clin Neuropharmacol 1992;15:63-68.

28. Ossemann M, Sindic CJ, Laterre C. Tetrabenazine as a cause of neuroleptic malignant syndrome. Mov Disord 1996;11:95.

29. Leonard DP, Kidson MA, Brown JG, Shannon PJ, Taryan S. A double blind trial of lithium carbonate and haloperidol in Huntington's chorea. Aust N Z J Psychiatry 1975;9:115-118.

30. Koller WC, Trimble J. The gait abnormality of Huntington's disease. Neurology 1985;35:1450-1454.

31. Quinn N, Marsden CD. A double blind trial of sulpiride in Huntington's disease and tardive dyskinesia. J Neurol Neurosurg Psychiatry 1984;47:844-847.

32. Deroover J, Baro F, Bourguignon RP, Smets P. Tiapride versus placebo: a double-blind comparative study in the management of Huntington's chorea. Curr Med Res Opin 1984;9:329-338.

33. Roos RA, Buruma OJ, Bruyn GW, Kemp B, van der Velde EA. 
Tiapride in the treatment of Huntington's chorea. Acta Neurol Scand 1982;65:45-50.

34. Bonelli R, Wenning G. Pharmacological management of Huntington's disease: an evidence-based review. Curr Pharm Des 2006; 12:2701-2720.

35. Gardner DM, Baldessarini RJ, Waraich P. Modern antipsychotic drugs: a critical overview. CMAJ 2005;172:1703-1711.

36. van Vugt JP, Siesling S, Vergeer M, van der Velde EA, Roos RA. Clozapine versus placebo in Huntington's disease: a double blind randomised comparative study. J Neurol Neurosurg Psychiatry 1997;63:35-39.

37. Caine ED, Polinsky RJ, Kartzinel R, Ebert MH. The trial use of clozapine for abnormal involuntary movement disorders. Am J Psychiatry 1979;136:317-320.

38. Bonuccelli U, Ceravolo R, Maremmani C, Nuti A, Rossi G, Muratorio A. Clozapine in Huntington's chorea. Neurology 1994; 44:821-823.

39. Sajatovic M, Verbanac P, Ramirez L, Meltzer H. Clozapine treatment of psychiatric symptoms resistant to neuroleptic treatment in patients with Huntington's chorea. Neurology 1991;41:156.

40. Vallette N, Gosselin O, Kahn JP. Efficacy of clozapine in the course of Huntington chorea: apropos of a clinical case [In French]. Encephale 2001;27:169-171.

41. Bonelli RM, Mahnert FA, Niederwieser G. Olanzapine for Huntington disease: an open label study. Clin Neuropharmacol 2002; 25:263-265.

42. Paleacu D, Anca M, Giladi N. Olanzapine in Huntington's disease. Acta Neurol Scand 2002;105:441-444.

43. Squitieri F, Cannella M, Piorcellini A, Brusa L, Simonelli M, Ruggieri S. Short-term effects of olanzapine in Huntington disease. Neuropsychiatry Neuropsychol Behav Neurol 2001;14:6972.

44. Laks J, Rocha M, Capitão C, et al. Functional and motor response to low dose olanzapine in Huntington's disease: case report. Arq Neuropsiquiatr 2004;62:1092-1094.

45. Jiménez-Jiménez FJ, de Toledo M, Puertas I, Barón M, Zurdo M, Barcenilla B. Olanzapine improves chorea in patients with Huntington's disease [In Spanish]. Rev Neurol 2002;35:524-525.

46. Bonelli RM, Niederwieser G, Tribl GG, Költringer P. High-dose olanzapine in Huntington's disease. Int Clin Psychopharmacol 2002;17:91-93.

47. Bogelman G, Hirschmann S, Modai I. Olanzapine and Huntington's disease. J Clin Psychopharmacol 2001;21:245-246.

48. Grove VE Jr, Quintanilla J, DeVaney GT. Improvement of Huntington's disease with olanzapine and valproate. N Engl J Med 2000;343:973-974.

49. Dipple H. The use of olanzapine for movement disorder in Huntington's disease: a first case report. J Neurol Neurosurg Psychiatry 1999;67:123-124.

50. Etchebehere EC, Lima MC, Passos W, et al. Brain SPECT imaging in Huntington's disease before and after therapy with olanzapine: case report. Arq Neuropsiquiatr 1999;57:863-866.

51. Cankurtaran ES, Ozalp E, Soygur H, Cakir A. Clinical experience with risperidone and memantine in the treatment of Huntington's disease. J Natl Med Assoc 2006;98:1353-1355.

52. Erdemoglu AK, Boratav C. Risperidone in chorea and psychosis of Huntington's disease. Eur J Neurol 2002;9:182-183.

53. Dallocchio C, Buffa C, Tinelli C, Mazzarello P. Effectiveness of risperidone in Huntington chorea patients. J Clin Psychopharmacol 1999;19:101-103.

54. Madhusoodanan S, Brenner R. Use of risperidone in psychosis associated with Huntington's disease. Am J Geriatr Psychiatry 1998;6:347-349.

55. Madhusoodanan S, Brenner R, Moise D, Sindagi J, Brafman I. Psychiatric and neuropsychological abnormalities in Huntington's disease: a case study. Ann Clin Psychiatry 1998;10:117120.

56. Parsa MA, Szigethy E, Voci JM, Meltzer HY. Risperidone in treatment of choreoathetosis of Huntington's disease. J Clin Psychopharmacol 1997;17:134-135.

57. Alpay M, Koroshetz WJ. Quetiapine in the treatment of behavioral disturbance in patients with Huntington's disease. Psychosomatics 2006;47:70-72.
58. Seitz DP, Millson RC. Quetiapine in the management of psychosis secondary to Huntington's disease: a case report. Can J Psychiatry 2004;49:413.

59. Bonelli RM, Niederwieser G. Quetiapine in Huntington's disease: a first case report. J Neurol 2002;249:1114-1115.

60. Bonelli RM, Mayr BM, Niederwieser G, Reisecker F, Kapfhammer HP. Ziprasidone in Huntington's disease: the first case reports. J Psychopharmacol 2003;17:459-460.

61. Verhagen Metman L, Morris MJ, Farmer C, et al. Huntington's disease: a randomized, controlled trial using the NMDA-antagonist amantadine. Neurology 2002;59:694-699.

62. Lucetti C, Del Dotto P, Gambaccini G, et al. IV amantadine improves chorea in Huntington's disease: an acute randomized, controlled study. Neurology 2003;60:1995-1997.

63. O'Suilleabhain P, Dewey RB Jr. A randomized trial of amantadine in Huntington disease. Arch Neurol 2003;60:996-998.

64. Heckmann JM, Legg P, Sklar D, Fine J, Bryer A, Kies B. IV amantadine improves chorea in Huntington's disease: an acute randomized, controlled study [Comment on Neurology 2003;60: 1995-1997]. Neurology 2004;63:597-598; author reply 597-598.

65. Kieburtz K, Feigin A, McDermott M, et al. A controlled trial of remacemide hydrochloride in Huntington's disease. Mov Disord 1996;11:273-277.

66. Huntington Study Group. A randomized, placebo-controlled trial of coenzyme Q10 and remacemide in Huntington's disease. Neurology 2001;57:397-404.

67. Beister A, Kraus P, Kuhn W, Dose M, Weindl A, Gerlach M. The $\mathrm{N}$-methyl-D-aspartate antagonist memantine retards progression of Huntington's disease. J Neural Transm Suppl 2004;68:117122.

68. Landwehrmeyer GB, Dubois B, de Yébenes JG. Riluzole in Huntington's disease: a 3-year, randomized controlled study. Ann Neurol 2007;62:262-272.

69. Huntington Study Group. Dosage effects of riluzole in Huntington's disease: a multicenter placebo-controlled study. Neurology 2003;61:1551-1556.

70. Rosas HD, Koroshetz WJ, Jenkins BG, et al. Riluzole therapy in Huntington's disease (HD). Mov Disord 1999;14:326-330.

71. Seppi K, Mueller J, Bodner T, et al. Riluzole in Huntington's disease (HD): an open label study with one year follow up. J Neurol 2001;248: 866-869.

72. Haaxma CA, Kremer HP, van de Warrenburg BP. Delayed amnesic syndrome after riluzole autointoxication in Huntington disease. Neurology 2006;66:1123-1124.

73. Bodner T, Jenner C, Benke T, Ober A, Seppi K, Fleischhacker WW. Intoxication with riluzole in Huntington's disease. Neurology 2001;57:1141-1143.

74. Kremer B, Clark CM, Almqvist EW, et al. Influence of lamotrigine on progression of early Huntington's disease: a randomized clinical trial. Neurology 1999;53:1000-1011.

75. Pearce I, Heathfield KW, Pearce MJ. Valproate sodium in Huntington chorea. Arch Neurol 1977;34:308-309.

76. Symington GR, Leonard DP, Shannon PJ, Vajda FJ. Sodium valproate in Huntington's disease. Am J Psychiatry 1978;135: 352-354.

77. Carella F, Scaioli V, Ciano C, Binelli S, Oliva D, Girotti F. Adult onset myoclonic Huntington's disease. Mov Disord 1993;8:201205.

78. Aoba S, Komiyama A, Yamada H, Hasegawa O. Action myoclonus in adult Huntington's disease [In Japanese]. Rinsho Shinkeigaku 1992;32:739-742.

79. Funakawa I, Kimura K, Jinnai K. Cortical reflex myoclonus in adult onset Huntington's disease [In Japanese]. Rinsho Shinkeigaku 2004;44:639-642.

80. Thompson PD, Bhatia KP, Brown P, et al. Cortical myoclonus in Huntington's disease. Mov Disord 1994;9:633-641.

81. Saft C, Lauter T, Kraus PH, Przuntek H, Andrich J. Dose-dependent improvement of myoclonic hyperkinesia due to valproic acid in eight Huntington's disease patients: a case series. BMC Neurol 2006;6:11.

82. Shoulson I, Odoroff C, Oakes D, et al. A controlled clinical trial of baclofen as protective therapy in early Huntington's disease. Ann Neurol 1989;25:252-259. 
83. Margineanu DG, Klitgaard H. Inhibition of neuronal hypersynchrony in vitro differentiates levetiracetam from classical antiepileptic drugs. Pharmacol Res 2000;42:281-285.

84. Zesiewicz TA, Sullivan KL, Hauser RA, Sanchez-Ramos J. Open-label pilot study of levetiracetam (Keppra) for the treatment of chorea in Huntington's disease. Mov Disord 2006;21:19982001.

85. de Tommaso M, Di Fruscolo O, Sciruicchio V, et al. Efficacy of levetiracetam in Huntington disease. Clin Neuropharmacol 2005; 28:280-284

86. Zesiewicz TA, Sanchez-Ramos J, Sullivan KL, Hauser RA. Levetiracetam-induced parkinsonism in a Huntington disease patient. Clin Neuropharmacol 2005;28:188-190.

87. Gatto EM, Roca CU, Etcheverry JL, Fadel D. Levetiracetaminduced parkinsonism in a Huntington's disease patient [Comment on Clin Neuropharmacol 2005;28:188-190]. Clin Neuropharmacol 2006;29:303-304.

88. Reuter I, Hu MT, Andrews TC, Brooks DJ, Clough C, Chaudhuri KR. Late onset levodopa responsive Huntington's disease with minimal chorea masquerading as Parkinson's plus syndrome. J Neurol Neurosurg Psychiatry 2000;68:238-241.

89. Racette BA, Perlmutter JS. Levodopa responsive parkinsonism in an adult with Huntington's disease. J Neurol Neurosurg Psychiatry 1998;65:577-579.

90. Bonelli RM, Niederwieser G, Diez J, Gruber A, Költringer P. Pramipexole ameliorates neurologic and psychiatric symptoms in a Westphal variant of Huntington's disease. Clin Neuropharmacol 2002;25:58-60.

91. Magnet MK, Kapfhammer HP, Bonelli RM. Cabergoline in Huntington's disease: the first case report. Acta Neurol Scand 2006; 113:355-356.

92. Cubo E, Shannon KM, Tracy D, et al. Effect of donepezil on motor and cognitive function in Huntington disease. Neurology 2006;67:1268-1271.

93. Fernandez HH, Friedman JH, Grace J, Beason-Hazen S. Donepezil for Huntington's disease. Mov Disord 2000;15:173-176.

94. de Tommaso M, Specchio N, Sciruicchio V, Difruscolo O, Specchio LM. Effects of rivastigmine on motor and cognitive impairment in Huntington's disease. Mov Disord 2004;19:1516-1518.

95. Petrikis P, Andreou C, Piachas A, Bozikas VP, Karavatos A Treatment of Huntington's disease with galantamine. Int Clin Psychopharmacol 2004;19:49-50.

96. Royuela Rico A, Gil-Verona JA, Macias Fernández JA. A case of obsessive symptoms in Huntington's disease [In Spanish]. Actas Esp Psiquiatr 2003;31:367-370.

97. Como PG, Rubin AJ, O'Brien CF, et al. A controlled trial of fluoxetine in nondepressed patients with Huntington's disease. Mov Disord 1997;12:397-401.

98. De Marchi N, Daniele F, Ragone MA. Fluoxetine in the treatment of Huntington disease. Psychopharmacology (Berl) 2001;153: 264-266.

99. Chari S, Quraishi SH, Jainer AK. Fluoxetine-induced exacerbation of chorea in Huntington's disease? A case report Pharmacopsychiatry 2003:36:41-43.

100. Patel SV, Tariot PN, Asnis J. L-Deprenyl augmentation of fluoxetine in a patient with Huntington's disease. Ann Clin Psychiatry 1996;8:23-26.

101. Patzold T, Brune M. Obsessive compulsive disorder in Huntington disease: a case of isolated obsessions successfully treated with sertraline. Neuropsychiatry Neuropsychol Behav Neurol 2002;15: 216-219.

102. Ranen NG, Lipsey JR, Treisman G, Ross CA. Sertraline in the treatment of severe aggressiveness in Huntington's disease. J Neuropsychiatry Clin Neurosci 1996;8:338-340.
103. Bonelli RM. Mirtazapine in suicidal Huntington's disease. Ann Pharmacother 2003;37:452.

104. Lewis CF, DeQuardo JR, Tandon R. ECT in genetically confirmed Huntington's disease. J Neuropsychiatry Clin Neurosci 1996;8:209-210.

105. Moro E, Lang AE, Strafella AP, et al. Bilateral globus pallidus stimulation for Huntington's disease. Ann Neurol 2004;56:290 294.

106. Hebb MO, Garcia R, Gaudet P, Mendez IM. Bilateral stimulation of the globus pallidus internus to treat choreathetosis in Huntington's disease: technical case report. Neurosurgery 2006;58:E383

107. Madrazo I, Franco-Bourland RE, Castrejon H, Cuevas C, Ostrosky-Solis F. Fetal striatal homotransplantation for Huntington's disease: first two case reports. Neurol Res 1995;17:312315.

108. Philpott LM, Kopyov OV, Lee AJ, et al. Neuropsychological functioning following fetal striatal transplantation in Huntington's chorea: three case presentations. Cell Transplant 1997;6: 203-212.

109. Kopyov OV, Jacques S, Lieberman A, Duma CM, Eagle KS. Safety of intrastriatal neurotransplantation for Huntington's disease patients. Exp Neurol 1998;149:97-108.

110. Bachoud-Lévi AC, Bourdet C, Brugières P, et al. Safety and tolerability assessment of intrastriatal neural allografts in five patients with Huntington's disease. Exp Neurol 2000;161:194202.

111. Bachoud-Lévi AC, Rémy P, Nguyen JP, et al. Motor and cognitive improvement in patients with Huntington's disease after neural transplantation. Lancet 2000;356:1975-1999.

112. Bachoud-Lévi A, Gaura V, Brugières $P$, et al. Effect of fetal neural transplants in patients with Huntington's disease 6 years after surgery: a long-term follow-up study. Lancet Neurol 2006; 5:303-309.

113. Hauser RA, Furtado S, Cimino CR, et al. Bilateral human fetal striatal transplantation in Huntington's disease. Neurology 2002; 28:687-695.

114. Freeman TB, Cicchetti F, Hauser RA, et al. Transplanted fetal striatum in Huntington's disease: phenotypic development and lack of pathology. Proc Natl Acad Sci U S A 2000;97:1387713882.

115. Keene CD, Sonnen JA, Swanson PD, et al. Neural transplantation in Huntington's disease: long-term grafts in two patients. Neurology 2007;68:2093-2098.

116. St. Hillaire M, Shannon K, Schumacher J, et al. Transplantation of fetal porcine striatal cells in Huntington's disease: preliminary safety and efficacy results. Neurology 1998;50(Suppl 4):A80A81 (abstract).

117. Tang TS, Chen X, Liu J, Bezprozvanny I. Dopaminergic signaling and striatal neurodegeneration in Huntington's disease. J Neurosci 2007;27:7899-7910.

118. Romero E, Cha GH, Verstreken P, et al. Suppression of neurodegeneration and increased neurotransmission caused by expanded full-length huntingtin accumulating in the cytoplasm. Neuron 2008;57:27-40.

119. Handley OJ, Naji JJ, Dunnett SB, Rosser AE. Pharmaceutical, cellular and genetic therapies for Huntington's disease. Clin Sci (Lond) 2006;110:73-88.

120. Wild EJ, Tabrizi SJ. Huntington's disease phenocopy syndromes. Curr Opin Neurol 2007;20:681-687.

121. Tan EK, Jankovic J, Ondo W. Bruxism in Huntington's disease. Mov Disord 2000;15:171-173.

122. McLellan DL, Chalmers RJ, Johnson RH. A double-blind trial of tetrabenazine, thiopropazate, and placebo in patients with chorea. Lancet 1974;1(7848):104-107. 